\title{
Crosstalk between circadian rhythms, sleep and eating habits to improve public health
}

\author{
Bovinder Chand* \\ Department of Zoology, Chaudhary Charan Singh University, Meerut-250004 (Uttar Pradesh), \\ India \\ Chandrapal Sharma \\ Department of Zoology, Chaudhary Charan Singh University, Meerut-250004 (Uttar Pradesh), \\ India \\ Sweekriti Malik \\ Department of Zoology, Chaudhary Charan Singh University, Meerut-250004 (Uttar Pradesh), \\ India \\ Neelu Jain Gupta \\ Department of Zoology, Chaudhary Charan Singh University, Meerut-250004 (Uttar Pradesh), \\ India \\ *Corresponding author. Email: bovinder_katoch@yahoo.co.in
}

\section{Article Info}

https://doi.org/10.31018/

jans.v13i4.3155

Received: October 28, 2021

Revised: December 3, 2021

Accepted: December 7, 2021

\section{How to Cite}

Chand, B. et al. (2021). Crosstalk between circadian rhythms, sleep and eating habits to improve public health. Journal of Applied and Natural Science, 13(4), 1470 - 1477. https://doi.org/10.31018/jans.v13i4.3155

\begin{abstract}
Lifestyle changes in the past few decades have resulted in irregularity in sleep and meal timings. People are taking less slep and resorting more to unhealthy food and eating habits. These factors are the most important health determinants. Sleep, food choices and eating habits are closely associated with each other. Thus, the crosstalk between circadian rhythms, sleep, and food needs urgent attention and discussion for better health management. Various research studies indicate that a healthy trend in sleep augments the regularity in meal timings and good eating habits. Healthy food and eating habits, in turn, boost sleep quality. Deterioration in the quality of anyone adversely affects the other. Several health disorders like obesity, diabetes, cancer, cardiovascular problems, and low immunity can be linked to these disturbances. The present review considers several previous studies to point out the inter-relationship between sleep and eating habits and the various health disorders arising from poor attention. Poor sleep promotes the tendency to eat junk food or eat at odd times, such as snacking late at night, leading to weight gain and other health problems. Junk food and unhealthy eating habits cause sleep disturbances. This inter-relationship of sleep and food preferences is important as it can have important treatment implications for health disorders arising due to these modifiable behavioural factors. Circadian alignment, improvements in sleep timings, and healthy eating habits have positive effects on other health behaviours as well.
\end{abstract}

Keywords: Circadian rhythms, Fast-food, Health, Lifestyle, Sleep

\section{INTRODUCTION}

Today's digital era with increased job hours and shift work has resulted in a society that has asleep and foodrelated issues like irregular sleep timings, reduced sleep duration, poor sleep quality, and unhealthy feeding habits (James et al., 2017). Sleep strongly regulates several physiological functions in the body, including metabolism, whereas food gives energy, controls growth and repair, and is also associated with immunity. Sleep and feeding pattern are affected by one another. Changes in sleep timings quite often result in changes in meal timings and feeding habits. Today's sleep-deprived busy life rapidly promotes unhealthy fast-food culture, which is associated with several adverse health consequences (Naito et al., 2021). There are several factors responsible for sleep deprivation. These can be attributed to profession-related compulsions or can be a result of the modern lifestyle. Modern lifestyle and technology have provided the opportunity to work pan-globe. This working style has various benefits which come at a cost. The countries located at different longitude have different time zones. Therefore people who are located at a time zone that is different from where they are providing services have to work at odd hours, compromising their sleep timing, pattern, 
and quality. The most common of which are business process outsourcing (BPOs) operating between countries (Taylor and Bain, 2005). Also, the $24^{*} 7$ working due to modernization and demand from companies operating continuously have led to a massive number of people working in shifts. A segment of these workers is deployed at night, compromising their sleep. The objective of the present review is to highlight some of the ill effects of present-day eating habits and sleep disruption due to changing lifestyles on human health with pieces of evidence available in scientific literature.

\section{EFFECT OF ARTIFICIAL LIGHT ON MELATONIN SECRETION}

Artificial light plays a significant role in disrupting sleep and biological processes controlled by endogenous circadian clocks (Lunn et al., 2017). It can be regarded as the single most important factor responsible for disrupting our major circadian systems, including sleep-wake and feeding-fasting, which regulate and play a chief role in our wellbeing. Melatonin secretion is suppressed and sleep onset latency is increased by exposure to artificial bright light during the nighttime (Cho et al., 2015). Artificial light at night affects melatonin secretion and causes sleep disturbances (Xiao et al., 2020). The role of melatonin has been found to augment and regulate circadian clocks. Melatonin secretion within the body gets affected by light-dark cycles is a fact established by numerous researchers. For example, a study found that melatonin secretion is suppressed beyond the light intensity of $\sim 400$ lux, if, continuous exposure is beyond 29 hours (Wever et al., 1983). In a similar study, the exposure to short-wavelength light with just a single pulse of 4 hours on the third day of a 4-day trial immediately after habitual wake time has been found to disrupt the circadian rhythms timings, altering the melatonin secretion (Warman et al., 2003). The most pronounced effect of artificial light on human life has been sleeping quality degradation resulting in reduced sleep duration and frequent sleep fragmentation.

\section{INTERNET USAGE AND SLEEP}

For almost the last two decades, the internet has become an inseparable part of our life. Keeping aside the work-related compulsions, in general, excessive internet usage like social media has played a great role in sleep disruption. The internet has crept into our lives like a necessary evil. Internet addiction is a new lifestyle disorder in human lives. Internet usage alters sleep rhythms (Rotunda et al., 2003). A recent study has demonstrated that internet addiction is associated with poor dietary habits, sleep problems, and fatigue symp- toms (Bener et al., 2019). Blue light emitted from computer screens, e-readers, and smartphone displays constitute a risk factor for sleep and circadian disorders (Hatori et al., 2017). Increased technology and social media use have resulted in fear of missing out (FoMO) and has been linked to negative health outcomes, including poor sleep hygiene (Rogers et al., 2019). High screen time exposure increases consumption frequencies of foods high in fat, free sugar, or salt, whereas long sleep duration may favourably be related to children's healthy food choices (Börnhorst et al., 2015).

\section{EFFECT OF SLEEP ON FOOD CHOICES, EATING HABITS AND HEALTH}

It is now a well-known fact that sleep plays a vital role in glucose regulation and cardiovascular function. It plays a major role in the central control of appetite and energy expenditure. Sleep loss results in decreased production of hormones like leptin and ghrelin, which have an essential role in glucose metabolism and the prevention of obesity (Cauter et al., 2008). Similarly, sleep parameters regulate food choices, and disrupted sleep indices are related to problematic eating behaviours (Ogilvie et al., 2018). A study by Kruger and coworkers found a significant association between food choices and sleep duration in adolescents (Kruger et al., 2014). Thus, considering the importance of the association between sleep and food choices in regulating health among adolescents, sleep quality and duration need urgent attention to reduce health-related issues.

A study involving 10,726 students in China revealed that $40 \%$ of them were taking a sleep of less than 8hour duration, indicating insufficient sleep among Chinese adolescents. Sleep insufficiency had a significant association with unhealthy food choices, whereas the longer sleep duration was associated with healthy eating habits. Adolescents with sufficient sleep reported a higher likelihood for milk, fruits, vegetables and water consumption. They were also found to be involved in moderate physical activity, including musclestrengthening physical activity. They have lower cigarette usage, lesser alcohol consumption, lower sweet intake or liking for western fast food, and lesser breakfast skipping than the students with a habit of lower sleep duration (Gong et al., 2017). Stamatakis and coworkers reported similar findings showing an association of short sleep duration with certain obesity-related behaviours in rural communities in Missouri, Tennessee, and Arkansas (Stamatakis and Brownson, 2008). Short sleep duration is particularly linked to lower physical activity along with low fruit and vegetable consumption which shows the importance of quality and duration of sleep on human health, manifested indirectly through food choices. Another similar study involving a sample 
comprising 1,75,261 adolescents from 64 countries, the examples of which include the USA, Australia, China, India, Latin America, and the Caribbean countries, pointed out the link between sleep deprivation and fastfood culture. In this study, $6.6 \%$ of males and $8.4 \%$ of females reported sleep disturbances. In both genders, it was found that there is a strong positive association of stress-related sleep disturbances with carbonated soft drinks and fast-food intake (Khan et al., 2020). Throughout the world, there is an increasing trend of smaller and nuclear families. Interestingly, smaller families have shown a preference for fast food and a trend of reduced sleep. A sample survey of teenage girls from nuclear families also shows a similar trend of preference for fast food and reduced sleep. Simultaneously they show significantly high-stress status, poor sleep quality, and higher odds of eating disorders (Rasouli et al., 2021). Late sleepers take sleep of shorter duration and they suffer from later sleep onset and early sleep offset and prefer delayed night-time meals. Late sleepers consume more calories at dinner and after 8 PM. They prefer fast food, high-calorie drinks, and lower fruits and vegetables (Baron et al., 2011). Adolescents and adults have similar sleep patterns and fast-food consumption, as pointed out in one of the studies in a sample of USA State police officers (Tewksbury and Copenhaver, 2015). Food preferences are directly linked to health. Obesity, diabetes, and gastrointestinal problems may be caused by excessive fast -food consumption. It can cause sleep deprivation and hyperactivity (Hardman, 2020). A study found that obese children with Obstructive Sleep Apnea (OSA) consumed 2.2 times more fast food. They ate fewer fruits and vegetables. They took 4.2 times lesser part in organized sports. OSA has been found to show a positive correlation with plasma ghrelin (orexigenic hormone or hunger hormone) levels (R2, 0.73; $P<.0001)$, but not visfatin levels, particularly when obesity was present. The severity of the underlying conditions may further be aggravated by these, as in persons with OSA, ghrelin increases the appetite and caloric intake (Spruyt et al., 2010). Short sleep increases appetite and hence obesity (Prinz, 2004).

Shorter sleep duration has been linked to reduced leptin, leading to increased body mass index (BMI) (Taheri et al., 2004). There is plenty of proof that obesity increases the risk for diabetes. Generally, older individuals are more obese and have more reported cases of diabetes. The risk for diabetes is increased by both the duration and magnitude of obesity (Bray, 1992). There is also ample proof that the population is at risk of developing obesity due to short sleep duration (Singh et al., 2005). The sleep duration for less than 12 hours in infants below the age of 3 years is linked with being overweight (Taveras et al., 2008). Similarly, the association between short sleep duration and obesity in young adults has also been reported (Hasler et al., 2004). Shift workers are always at a greater risk of obesity; for example, short sleep duration related to work in truck drivers has been proved to cause obesity (Moreno et al., 2006). The professions involving long working hours may force the person to take sleep for a shorter duration resulting in increased BMl (Magee et al., 2011). As already mentioned, the effect of sleep disruption is exhibited chiefly through leptin levels. Because the short sleep duration diminishes the leptin level in the body, it increases the adiposity causing obesity (Chaput et al., 2007). Early sleeping at night improves breakfast choices and helps in obesity prevention during adolescence (Asarnow et al., 2017). Daily energy intake and fat, protein, and carbohydrate intake are increased with partial sleep restriction with a duration of $\leq 5.5 \mathrm{~h}$ day $^{-1}$ (Fenton et al., 2021).

Increased risk for diabetes results from abnormal glucose metabolism and there are shreds of evidence for the link between diabetes and sleep insufficiency and sleep disruption (Reutrakul and Cauter, 2014). Prolonged sleep restriction decreases the metabolic rate, increasing the plasma glucose concentration after a meal due to inadequate pancreatic insulin secretion, leading to diabetic conditions (Buxton et al., 2012). A large proportion of the world population is now involved in shift work. For example, 1.5 million of the Australian population is engaged in professions involving shift work. Several sleep disorders are linked with shift work, including insomnia, excessive sleepiness, or sleep apnea (Rajaratnam et al., 2013). A study indicated that shift workers generally prefer fast food or eat cold food (Strzemecka et al., 2014). In a study involving a sample of nurses engaged in shift work in Turkey, they have been found to take higher energy food than those without shift work (1756 $\pm 659 \mathrm{kcal}$ versus $1694 \pm 431 \mathrm{kcal}, \mathrm{p}>0.05)$. They were found to consume higher carbohydrates \& fats but significantly lesser proteins (Varli and Bilici, 2016). Shift work lowers both quality and quantity of sleep, as manifested in a study involving a sample population of shift workers composed of 65 males and 44 females, aged between 18 and 64 years from Europe. Very high proportions $(48 \%)$ were found overweight or obese. There was complete consensus on the reduction of sleep quality and quantity. Most of them described their eating habits as 'irregular', 'erratic', and 'rushed' with negative trends of eating patterns and poor nutritional quality of foods consumed. $30 \%$ of the volunteers reported reduced weekly physical activity with only once or even less, with a little cardiovascular workout. Smoking levels were reported significantly higher. The respondents reported negative impacts on mental health due to shift work (Nea et al., 2018). 


\section{EFFECT OF FOOD ON SLEEP QUALITY AND SLEEP DURATION}

Not only the sleep quality and duration regulate food choices or eating habits, but the vice-versa effect of food on sleep regulation is also seen. There are numerous shreds of evidence of the link between diet and sleep. In the developed parts of the world as well as in the developing and third world countries like India, Brazil, Argentina, Guyana, South Africa, Latin American countries, there is a rapid lifestyle change. Throughout the world, the trends of poor sleep quality and unhealthy eating habits are very much similar. Normally, humans are expected to take three meals a day: in the morning, afternoon and night, but in the present times, people are taking a calorific diet more than three times a day with irregular meal timings.

In most cases, our eating window exceeds 15 hours a day. For instance, a camera phone-based study found disrupted feeding fasting cycles and patterns among adults in India, which may have several adverse consequences on health (Gupta et al., 2017). Not only in adults but, similar patterns have also been observed and reported for school-going Indian adolescents (Gupta and Khare, 2020). Similarly, in Indian working women, an increasing trend of disruption in feedingfasting has been found along with disruption in other circadian routines (Gupta, 2019). As already mentioned, this may be due to their work-related compulsions or the rapidly growing fast-food culture. The study conducted by St-Onge et al. (2016) elucidates the role of diet on sleep. They have concluded that healthy food choices in the general population with increasing fruits and vegetable intake, choosing whole grains (higher in fibre), and favouring vegetable oil can benefit good sleep. Healthy food choices promote good sleep (Peuhkuri et al., 2012). Late-night food eating habits negatively affect the sleep quality in healthy individuals (Crispim et al., 2011). By analyzing the conclusion of the above studies, it is clear that sleep deprivation promotes unhealthy food choices and unhealthy food choices lead to sleep problems like sleep degradation and deprivation, strongly indicating a link between these two.

\section{EFFECT OF SLEEP, FOOD AND LIFESTYLE ON DIABETES}

Lifestyle changes resulting in alteration of sleep and food parameters can be held responsible for several health disorders. Among these, diabetes deserves special attention as diabetes is affecting a large part of the population throughout the globe. Keeping aside the genetic reasons, lifestyle changes are a direct suspect for increasing type- 2 diabetes mellitus cases. Diabetes affects all age groups without any gender bias. A sample survey indicated $12.1 \%$ cases of diabetes and $14.0 \%$ cases of glucose intolerance without any gender difference in India. Diabetes has a direct and independent association with age, BMI, Waist-to-Hip-Ratio (WHR), and family history of diabetes. Another interesting finding is the direct relationship between monthly income and sedentary physical activity resulting in diabetes. Glucose intolerance has a positive association with BMI, age, and family history of diabetes (Ramachandran et al., 2001). The problem with diabetes is that it leads to several other comorbidities also. In a survey of newly diagnosed 4,600 diabetic patients aged $41-50$ years, $1.06 \%$ had nephropathy, $6.1 \%$ had retinopathy, and $13.15 \%$ had neuropathy. Among these, $23.3 \%$ had hypertension, $26 \%$ had obesity, $27 \%$ had dyslipidemia, and ischemic heart disease was found in 6\% (Sosale et al., 2014). An analytical study from a tertiary care hospital in North India found that at least $2.7 \%$ or 592 of the total deaths were linked to diabetes among the 21,584 deaths of $3,06,652$ patients admitted between 1991- 1999 (Bhansali et al., 2003). Circadian systems regulate sugar metabolism, and disruption in these may cause obesity and diabetes. These may include disrupted light-dark, sleep-wake, and feeding-fasting cycles (Taheri, 2006 and Watanabe et al., 2010). Diabetes results from the dysfunction of mitochondria in $\beta$-cells of the pancreas, leading to oxidative stress in $\beta$-cells which causes lower secretion of vital glucose metabolism hormone, i.e., insulin. This dysfunction of mitochondria may be due to disruption of the central or peripheral ( $\beta$-cell) clock along with several other factors (Lee et al., 2018). Metabolic deregulation arises from circadian disruption, insufficiency of sleep, and altering the meal amount and timings, leading to weight gain, obesity, and ultimately to type 2 diabetes (Depner et al., 2014 and Javeed et al., 2018).

\section{EFFECT ON CARDIOVASCULAR HEALTH}

Increased BMI and obesity have a direct link with cardiovascular diseases. Circadian disruption arising from shift work, jet lag, late eating, and sleep-wake disturbances increase the cardiovascular risk factors (Rüger et al., 2009 and Chellappa et al., 2019). Sleep duration of fewer than 6 hours is risky and induces the development of chronic diseases, particularly hypertension, cardiovascular disorders, stroke, and cancer (Rüger et al., 2012). Women with sleep debt are more likely to be obese and have hypertension with an increased risk of cardiovascular disorders (Cabeza et al., 2019). Circadian disruption plays a role in the onset and development of cardiovascular (CV) disease, and treatments to mitigate circadian disruption may diminish CV risk (Chalupa et al., 2019). Sleep restriction increas- 
es food intake and causes cardiovascular disorders, whereas better sleep habits are associated with good cardiovascular health among women (Makarem et al., 2019). Similar to adults, in children and adolescents also, there is strong evidence on the association between short sleep duration and increased adiposity markers and high blood pressure (Sun et al., 2020).

\section{A CAUSE OF CANCER}

Unhealthy food, sleep apnea and escalated BMI are also interlinked with many types of cancer. (Sugimura, 2002 and Seidell, 2010). Disruption of the circadian clock damages the organization of the gene regulating the cell cycle and protein expressions, leading to deregulated cell proliferation and subsequent tumorigenesis (Savvidis and Koutsilieris, 2012). A significantly increased risk for breast cancer was reported in Japanese women who slept 6 hours or less on average (Kakizaki et al., 2008). Possibly due to greater overall melatonin production in long sleepers, there is an inverse association between sleep duration and breast cancer risk in women (Verkasalo et al., 2005). Similarly, Unhealthy food choices may be associated with an increase in breast cancer risk (Deschasaux et al., 2017). In postmenopausal women, both extremely short and long sleep durations increase the risk of colorectal tumorigenesis (Jiao et al., 2013). An inverse association has also been observed between sleep duration and risk for prostate cancer (Kakizaki et al., 2008). Analysis of association between the British FSA-NPS (Food Standards Agency Nutrient Profiling System) individual score and cancer risk indicates that there may be a 34 $\%$ increase in overall cancer risk due to unhealthy food choices (Donnenfeld et al., 2015). Like food choices, eating habits, and sleep rhythms are interlinked, their overall impact on the pathogenicity of cancer may also be affected by each other.

\section{EFFECT ON IMMUNITY}

In the tough times of health crisis due to the current COVID-19 pandemic, immunity is very important for survival and to offset the effects of novel coronavirus. There is a need to study the role of circadian systems especially involved in regulating sleep and eating preferences for the current pandemic. Sleep and healthy circadian rhythms act as immunity boosters for inpatients and help faster recovery in many ailments. So, hospital management should provide an environment with uninterrupted proper sleep to inpatients (Tan et al., 2019). There is also a need to determine the role of OSA in the risk of COVID-19 infection and its severity (Tufik et al., 2020). Both sleep and food play a vital role in immunity. So, sleep, food, and eating habits could have a possible role in managing the severity and risk of Covid-19. Comorbidities like hypertension, cardiovascular disease, diabetes, chronic respiratory disease, chronic kidney disease (CKD), and cancer increase the risk of mortality in COVID-19 patients (Shahid et al., 2020 and Assaad, 2020). In the list of several other factors that can cause these comorbidities, the circadian disruption of sleep and feeding fasting cycles also find a place. Therefore, the importance of crosstalk between circadian rhythms, sleep and eating habits' implications in human health management can be understood.

\section{Conclusion}

The study concluded that sleep and food choices affect each other. There is a significant role of crosstalk between circadian rhythms, sleep and food safety implications in human health management as sleep and food are the most important health determinants. Disturbance in one factor degrades the quality of another. Reduction in sleep quality and duration leads to unhealthy food choices and irregular meal timings. In turn, unhealthy food choices and irregular meal timing reduce sleep quality and quantity. Sleep and food affect our immunity and health directly. There are a lot of adverse health consequences which arise due to sleep degradation and unhealthy food choices. Focusing on sleep quality, duration, and eating habits can be highly important for the risk management of several health disorders.

\section{Conflict of interest}

The authors declare that they have no conflict of interest.

\section{REFERENCES}

1. Asarnow, L. D., Greer, S. M., Walker, M. P., \& Harvey, A. G. (2017). The impact of sleep improvement on food choices in adolescents with late bedtimes. Journal of Adolescent Health, 60(5), 570-576.

2. Assaad, S., Avrillon, V., Fournier, M. L., Mastroianni, B., Russias, B., Swalduz, A., $\quad$ Cassier, P., Eberst, L., Steineur, M. P., Kazes, M., Perol, M., Michallet, A. S., Rey, P., Erena-Penet, A. S., Morel, A., Brahmi, M., Dufresne, A., Tredan, O., Chvetzoff, G., Fayette, J., de la Fouchardiere, C., Ray-Coquard, I., Bachelot, T., Saintigny, P., Tabutin, M., Dupré, A., Nicolas-Virelizier, E., Belhabri, A., Roux, P. E., Fuhrmann, C., Pilleul, F., Basle, A., Bouhamama, A., Galvez, C., Herr, A. L., Gautier, J., Chabaud,S., Zrounba, P., Perol, D.\& Blay, J. Y. (2020). High mortality rate in cancer patients with symptoms of COVID-19 with or without detectable SARS-COV-2 on RT-PCR. European Journal of Cancer (Oxford, England: 1990), 135, 251-259. doi.org/10.1016/j.ejca.2020.05.028

3. Baron, K. G., Reid, K. J., Kern, A. S. \& Zee, P. C. (2011). Role of sleep timing in caloric intake and BMI. Obesity 
(Silver Spring, Md.), 19(7), 1374-1381. doi.org/10.1038/ oby.2011.100

4. Bener, A., Yildirim, E., Torun, P., Catan, F., Bolat, E., Alic, S., Akyel, S. \& Griffiths, M. D. (2019). Internet Addiction, Fatigue, and Sleep Problems Among Adolescent Students: a Large-Scale Study. Int J Ment Health Addiction, 17, 959-969. doi.org/10.1007/s11469-018-9937-1

5. Bhansali, A., Chattopadhyay, A. \& Dash, R. J. (2003). Mortality in diabetes: a retrospective analysis from a tertiary care hospital in North India. Diabetes Research and Clinical Practice, 60(2), 119-124. doi.org/10.1016/s01688227(03)00013-5

6. Börnhorst, C., Wijnhoven, T. M., Kunešová, M., Yngve, A., Rito, A. I., Lissner, L., ... \& Breda, J. (2015). WHO European Childhood Obesity Surveillance Initiative: associations between sleep duration, screen time and food consumption frequencies. BMC Public Health, 15(1), 1-11.

7. Bray G. A. (1992). Obesity increases risk for diabetes. International journal of obesity and related metabolic disorders: journal of the International Association for the Study of Obesity, 16 Suppl 4, S13-S17.

8. Buxton, O. M., Cain, S. W., O'Connor, S. P., Porter, J. H., Duffy, J. F., Wang, W., Czeisler, C. A. \& Shea, S. A. (2012). Adverse metabolic consequences in humans of prolonged sleep restriction combined with circadian disruption. Science Translational Medicine, 4(129), 129ra43. doi.org/10.1126/scitranslmed.3003200

9. Cabeza de Baca, T., Chayama, K. L., Redline, S., Slopen, N., Matsushita, F., Prather, A. A., ... \& Albert, M. A. (2019). Sleep debt: the impact of weekday sleep deprivation on cardiovascular health in older women. Sleep, 42 (10), zsz149.

10. Chalupa, S. L., Vujovic, N., Williams, J. S., \& Scheer, F. A. (2019). Impact of circadian disruption on cardiovascular function and disease. Trends in Endocrinology \& Metabolism, 30(10), 767-779.

11. Chaput, J. P., Després, J. P., Bouchard, C. \& Tremblay, A. (2007). Short sleep duration is associated with reduced leptin levels and increased adiposity: Results from the Quebec family study. Obesity (Silver Spring, Md.), 15(1), 253-261. doi.org/10.1038/oby.2007.512

12. Chellappa, S. L., Vujovic, N., Williams, J. S. \& Scheer, F. (2019). Impact of Circadian Disruption on Cardiovascular Function and Disease. Trends in Endocrinology and Metabolism: TEM, 30(10), 767-779. doi.org/10.1016/ j.tem.2019.07.008

13. Cho, Y., Ryu, S. H., Lee, B. R., Kim, K. H., Lee, E., \& Choi, J. (2015). Effects of artificial light at night on human health: A literature review of observational and experimental studies applied to exposure assessment. Chronobiology International, 32(9), 1294-1310.

14. Crispim, C. A., Zimberg, I. Z., dos Reis, B. G., Diniz, R. M., Tufik, S. \& de Mello, M. T. (2011). Relationship between food intake and sleep pattern in healthy individuals. Journal of clinical sleep medicine, 7(6), 659-664. doi.org/10.5664/jcsm.1476

15. Depner, C. M., Stothard, E. R. \& Wright, K. P., Jr (2014). Metabolic consequences of sleep and circadian disorders. Current Diabetes Reports, 14(7), 507. doi.org/10.1007/ s11892-014-0507-z

16. Deschasaux, M., Julia, C., Kesse-Guyot, E., Lécuyer, L., Adriouch, S., Méjean, C., ... \& Touvier, M. (2017). Are self -reported unhealthy food choices associated with an increased risk of breast cancer? Prospective cohort study using the British Food Standards Agency nutrient profiling system. BMJ open, 7(6), e013718.

17. Donnenfeld, M., Julia, C., Kesse-Guyot, E., Méjean, C., Ducrot, P., Péneau, S. \& Touvier, M. (2015). Prospective association between cancer risk and an individual dietary index based on the British Food Standards Agency Nutrient Profiling System. British Journal of Nutrition, 114(10), 1702-1710.

18. Fenton, S., Burrows, T. L., Skinner, J. A., \& Duncan, M. J. (2021). The influence of sleep health on dietary intake: a systematic review and meta $\square$ analysis of intervention studies. Journal of Human Nutrition and Dietetics, 34(2), 273285.

19. Gong, Q. H., Li, H., Zhang, X. H., Zhang, T., Cui, J. \& Xu, G. Z. (2017). Associations between sleep duration and physical activity and dietary behaviors in Chinese adolescents: results from the Youth Behavioral Risk Factor Surveys of 2015. Sleep Medicine, 37, 168-173. doi.org/10.1016/j.sleep.2017.06.024

20. Gupta, N. J. \& Khare, A. (2020). Disruption in daily eatingfasting and activity-rest cycles in Indian adolescents attending school. PloS one, 15(1), e0227002. doi.o rg/10.1371/journal.pone.0227002

21. Gupta, N. J. (2019). Lifestyle and Circadian Health: Where the Challenges Lie? Nutrition and Metabolic Insights, 12, 1178638819869024. doi.org/10.1177/1178638819869024

22. Gupta, N. J., Kumar, V. \& Panda, S. (2017). A cameraphone based study reveals erratic eating pattern and disrupted daily eating-fasting cycle among adults in India. PloS one, 12(3), e0172852. doi.org/10.1371/ journal.pone. 0172852

23. Hatori, M., Gronfier, C., Van Gelder, R. N., Bernstein, P. S., Carreras, J., Panda, S. ... \& Tsubota, K. (2017). Global rise of potential health hazards caused by blue lightinduced circadian disruption in modern aging societies. NPJ Aging and Mechanisms of Disease, 3(1), 1-3.

24. Hardman, M. (2020). Council Motion - Ban on fast food and energy drink advertising. Health Scrutiny Committee. Retrieved from https://committees.oldham.gov.uk/ documents/s117112/20200707\%20Health\%20Scrutiny\% 20-\%20Fast\%20Food\%20Motion\%20report.pdf

25. Hasler, G., Buysse, D. J., Klaghofer, R., Gamma, A., Ajdacic, V., Eich, D., Rössler, W. \& Angst, J. (2004). The association between short sleep duration and obesity in young adults: a 13-year prospective study. Sleep, 27(4), 661-666. doi.org/10.1093/sleep/27.4.661

26. James, S. M., Honn, K. A., Gaddameedhi, S., \& Van Dongen, H. P. (2017). Shift work: disrupted circadian rhythms and sleep-implications for health and wellbeing. Current Sleep Medicine Reports, 3(2), 104-112.

27. Javeed, N. \& Matveyenko, A. V. (2018). Circadian Etiology of Type 2 Diabetes Mellitus. Physiology (Bethesda, Md.), 33(2), 138-150. doi.org/10.1152/physiol.00003.2018

28. Jiao, L., Duan, Z., Sangi-Haghpeykar, H., Hale, L., White, D. L., \& El-Serag, H. (2013). Sleep duration and incidence of colorectal cancer in postmenopausal women. British Journal of Cancer, 108(1), 213-221.

29. Kakizaki, M., Inoue, K., Kuriyama, S., Sone, T., MatsudaOhmori, K., Nakaya, N., ... \& Tsuji, I. (2008). Sleep duration and the risk of prostate cancer: the Ohsaki Cohort 
Chand, B. et al. / J. Appl. \& Nat. Sci. 13(4), 1470 - 1477 (2021)

Study. British Journal of Cancer, 99(1), 176-178.

30. Kakizaki, M., Kuriyama, S., Sone, T., Ohmori-Matsuda, K., Hozawa, A., Nakaya, N., ... \& Tsuji, I. (2008). Sleep duration and the risk of breast cancer: the Ohsaki Cohort Study. British Journal of Cancer, 99(9), 1502-1505.

31. Khan, A., Dix, C., Burton, N. W., Khan, S. R. \& Uddin, R. (2020). Association of carbonated soft drink and fast-food intake with stress-related sleep disturbance among adolescents: A global perspective from 64 countries. E Clinical Medicine, 31, 100681. doi.org/10.1016/ j.eclinm.2020.100681

32. Kruger, A. K., Reither, E. N., Peppard, P. E., Krueger, P. M. \& Hale, L. (2014). Do sleep-deprived adolescents make less-healthy food choices? The British Journal of Nutrition, 111(10), 1898-1904. doi.org/10.1017/ S0007114514000130

33. Lee, J., Ma, K., Moulik, M. \& Yechoor, V. (2018). Untimely oxidative stress in $\beta$-cells leads to diabetes - Role of circadian clock in $\beta$-cell function. Free Radical Biology \& Medicine, 119, 69-74. doi.org/10.1016/j.freerad biomed.2018.02.022

34. Lunn, R. M., Blask, D. E., Coogan, A. N., Figueiro, M. G., Gorman, M. R., Hall, J. E., Hansen, J., Nelson, R. J., Panda, S., Smolensky, M. H., Stevens, R. G., Turek, F. W., Vermeulen, R., Carreón, T., Caruso, C. C., Lawson, C. C., Thayer, K. A., Twery, M. J., Ewens, A. D., Garner, S. C. Schwingl, P. J. \& Boyd, W. A. (2017). Health consequences of electric lighting practices in the modern world: A report on the National Toxicology Program's workshop on shift work at night, artificial light at night, and circadian disruption. The Science of the Total Environment, 607608, 1073-1084. doi.org/10.1016/j.scitotenv.2017.07.056

35. Magee, C. A., Caputi, P. \& Iverson, D. C. (2011). Short sleep mediates the association between long work hours and increased body mass index. Journal of Behavioral Medicine, 34(2), 83-91. doi.org/10.1007/s10865-010-92 87-3

36. Makarem, N., St-Onge, M. P., Liao, M., Lloyd-Jones, D. M., \& Aggarwal, B. (2019). Association of sleep characteristics with cardiovascular health among women and differences by race/ethnicity and menopausal status: findings from the American Heart Association Go Red for Women Strategically Focused Research Network. Sleep Health, 5 (5), 501-508.

37. Moreno, C. R., Louzada, F. M., Teixeira, L. R., Borges, F. \& Lorenzi-Filho, G. (2006). Short sleep is associated with obesity among truck drivers. Chronobiology International, 23(6), 1295-1303. doi.org/10.1080/07420520601089521

38. Naito, R., Yun Low, W., \& Wan Yuen, C. (2021). Sleep Deprivation and Its Associated Factors Among Undergraduate Students in Malaysia. Asia Pacific Journal of Public Health, 10105395211019930.

39. Nea, F. M., Pourshahidi, L. K., Kearney, J. M., Livingstone, M., Bassul, C. \& Corish, C. A. (2018). A qualitative exploration of the shift work experience: the perceived effect on eating habits, lifestyle behaviours and psychosocial wellbeing. Journal of Public Health (Oxford, England), 40(4), e482-e492. doi.org/10.1093/pubmed/fdy047

40. Ogilvie, R. P., Lutsey, P. L., Widome, R., Laska, M. N., Larson, N. \& Neumark-Sztainer, D. (2018). Sleep indices and eating behaviours in young adults: findings from Project EAT. Public Health Nutrition, 21(4), 689-701.
doi.org/10.1017/S1368980017003536

41. Peuhkuri, K., Sihvola, N. \& Korpela, R. (2012). Diet promotes sleep duration and quality. Nutrition Research (New York, N.Y.), 32(5), 309-319. doi.org/10.1016/j.nutres.20 12.03.009

42. Prinz, P. (2004). Sleep, appetite, and obesity--what is the link? PLoS Medicine, 1(3), e61. doi.org/10.1371/jour nal.pmed.0010061

43. Rajaratnam, S. M., Howard, M. E. \& Grunstein, R. R (2013). Sleep loss and circadian disruption in shift work: health burden and management. The Medical Journal of Australia, 199(8), S11-S15. doi.org/10.5694/mja13.10561

44. Ramachandran, A., Snehalatha, C., Kapur, A., Vijay, V., Mohan, V., Das, A. K., Rao, P. V., Yajnik, C. S., Prasanna Kumar, K. M., Nair, J. D. \& Diabetes Epidemiology Study Group in India (DESI) (2001). High prevalence of diabetes and impaired glucose tolerance in India: National Urban Diabetes Survey. Diabetologia, 44(9), 1094-1101. doi.org/10.1007/s001250100627

45. Rasouli, A., Mohiti, S., Javadi, M., Panjeshahin, A., Kazemi, M. \& Shiri-Shahsavar, M. R. (2021). The effect of daily fast food consumption, family size, weight-caused stress, and sleep quality on eating disorder risk in teenagers. Sleep \& Breathing = Schlaf \& Atmung, 25(3), 15271533. doi.org/10.1007/s11325-020-02189-9

46. Reutrakul, S. \& Van Cauter, E. (2014). Interactions between sleep, circadian function, and glucose metabolism: implications for risk and severity of diabetes. Annals of the New York Academy of Sciences, 1311, 151-173. doi.org/10.1111/nyas. 12355

47. Rogers, A. P., \& Barber, L. K. (2019). Addressing FoMO and telepressure among university students: Could a technology intervention help with social media use and sleep disruption? Computers in Human Behavior, 93, 192-199.

48. Rotunda, R. J., Kass, S. J., Sutton, M. A., \& Leon, D. T. (2003). Internet use and misuse: Preliminary findings from a new assessment instrument. Behavior Modification, 27 (4), 484-504

49. Rüger, M. \& Scheer, F. A. (2009). Effects of circadian disruption on the cardiometabolic system. Reviews in Endocrine \& Metabolic Disorders, 10(4), 245-260. doi.org/10.1007/s11154-009-9122-8

50. Savvidis, C., \& Koutsilieris, M. (2012). Circadian rhythm disruption in cancer biology. Molecular Medicine, 18(9), 1249-1260.

51. Seidell J. C. (2010). Waist circumference and waist/hip ratio in relation to all-cause mortality, cancer and sleep apnea. European Journal of Clinical Nutrition, 64(1), 3541. doi.org/10.1038/ejcn.2009.71

52. Shahid, Z., Kalayanamitra, R., McClafferty, B., Kepko, D., Ramgobin, D., Patel, R., Aggarwal, C. S., Vunnam, R., Sahu, N., Bhatt, D., Jones, K., Golamari, R. \& Jain, R. (2020). COVID-19 and Older Adults: What We Know. Journal of the American Geriatrics Society, 68(5), 926929. doi.org/10.1111/jgs.16472

53. Singh, M., Drake, C. L., Roehrs, T., Hudgel, D. W. \& Roth, T. (2005). The association between obesity and short sleep duration: a population-based study. Journal of Clinical Sleep Medicine, 1(4), 357-363.

54. Sosale, A., Prasanna Kumar, K. M., Sadikot, S. M., Nigam, A., Bajaj, S., Zargar, A. H. \& Singh, S. K. (2014). Chronic complications in newly diagnosed patients with 
Type 2 diabetes mellitus in India. Indian Journal of Endocrinology and Metabolism, 18(3), 355-360. doi.org/1 $0.4103 / 2230-8210.131184$

55. Spruyt, K., Sans Capdevila, O., Serpero, L. D., Kheirandish-Gozal, L. \& Gozal, D. (2010). Dietary and physical activity patterns in children with obstructive sleep apnea. The Journal of Pediatrics, 156(5), 724-730.e3 doi.org/10.1016/j.jpeds.2009.11.010

56. Stamatakis, K. A. \& Brownson, R. C. (2008). Sleep duration and obesity-related risk factors in the rural Midwest. Preventive Medicine, 46(5), 439-444. doi.org/10.1016/ j.ypmed.2007.11.008

57. St-Onge, M. P., Mikic, A. \& Pietrolungo, C. E. (2016). Effects of Diet on Sleep Quality. Advances in Nutrition (Bethesda, Md.), 7(5), 938-949. doi.org/10.3945/an.1 16.012336

58. Strzemecka, J., Bojar, I., Strzemecka, E. \& Owoc, A. (2014). Dietary habits among persons hired on shift work. Annals of Agricultural and Environmental Medicine: AAEM, 21(1), 128-131.

59. Sugimura T. (2002). Food and cancer. Toxicology, 181 182, 17-21. doi.org/10.1016/s0300-483x(02)00250-0

60. Sun, J., Wang, M., Yang, L., Zhao, M., Bovet, P. \& Xi, B. (2020). Sleep duration and cardiovascular risk factors in children and adolescents: a systematic review. Sleep medicine reviews, 53, 101338.

61. Taheri S. (2006). The link between short sleep duration and obesity: we should recommend more sleep to prevent obesity. Archives of Disease in Childhood, 91(11), 881884. doi.org/10.1136/adc.2005.093013

62. Taheri, S., Lin, L., Austin, D., Young, T. \& Mignot, E. (2004). Short sleep duration is associated with reduced leptin, elevated ghrelin, and increased body mass index. PLoS Medicine, 1(3), e62. doi.org/10.1371/ journal.pmed.0010062

63. Tan, X., van Egmond, L., Partinen, M., Lange, T. \& Benedict, C. (2019). A narrative review of interventions for improving sleep and reducing circadian disruption in medical inpatients. Sleep Medicine, 59, 42-50. doi.org/10.1016/ j.sleep.2018.08.007

64. Taveras, E. M., Rifas-Shiman, S. L., Oken, E., Gunderson, E. P. \& Gillman, M. W. (2008). Short sleep duration in infancy and risk of childhood overweight. Archives of Pediatrics \& Adolescent Medicine, 162(4), 305-311. doi.org/10.1001/archpedi.162.4.305

65. Taylor, P., \& Bain, P. (2005). 'India calling to the far away towns' the call centre labour process and globalization. Work, employment and society, 19(2), 261-282.

66. Tewksbury, R. \& Copenhaver, A. (2015). State police officer sleep patterns and fast-food consumption. International Journal of Police Science \& Management, 17(4), 230- 236. doi:10.1177/1461355715617343

67. Tufik, S., Gozal, D., Ishikura, I. A., Pires, G. N. \& Andersen, M. L. (2020). Does obstructive sleep apnea lead to increased risk of COVID-19 infection and severity? Journal of Clinical Sleep Medicine, 16(8), 1425-1426. doi.org/10.5664/jcsm.8596

68. Cauter, E. Van, Spiegel, K., Tasali, E. \& Leproult, R. (2008). Metabolic consequences of sleep and sleep loss. Sleep Medicine, 9 Suppl 1(0 1), S23-S28. doi.org/10.10 16/S1389-9457(08)70013-3

69. Varli, S. N. \& Bilici, S. (2016). The nutritional status of nurses working shifts: A pilot study in Turkey. Revista De Nutricao- Brazilian Journal of Nutrition, 29(4), 589-596. doi.org/10.1590/1678-98652016000400013

70. Verkasalo, P. K., Lillberg, K., Stevens, R. G., Hublin, C., Partinen, M., Koskenvuo, M., \& Kaprio, J. (2005). Sleep duration and breast cancer: a prospective cohort study. Cancer Rresearch, 65(20), 9595-9600.

71. Warman, V. L., Dijk, D. J., Warman, G. R., Arendt, J. \& Skene, D. J. (2003). Phase advancing human circadian rhythms with short wavelength light. Neuroscience Letters, 342(1-2), 37-40. doi.org/10.1016/s0304-3940(03)00223-4

72. Watanabe, M., Kikuchi, H., Tanaka, K. \& Takahashi, M. (2010). Association of short sleep duration with weight gain and obesity at 1-year follow-up: a large-scale prospective study. Sleep, 33(2), 161-167. doi.org/10.1093/ sleep/33.2.161

73. Wever, R. A., Polásek, J. \& Wildgruber, C. M. (1983). Bright light affects human circadian rhythms. Pflugers Archiv: European Journal of Physiology, 396(1), 85-87. doi.org/10.1007/BF00584704

74. Xiao, Q., Gee, G., Jones, R. R., Jia, P., James, P., \& Hale, L. (2020). Cross-sectional association between outdoor artificial light at night and sleep duration in middle-toolder aged adults: the NIH-AARP Diet and Health Study. Environmental Research, 180, 108823. 